Dept. Surgery \& Theriog.,

Faculty Vet. Med., Alexandria University,

Head of Dept. Prof. Dr. M.Y. Abboud.

\title{
THE INFLUENCE OF ABOMASAL DISTENSION ON GASTRO-INTESTINAL MOTILITY IN GOATS (With One Fig.)
}

\section{By \\ M.M. KASSEM; D.R. NELSON* and H.A. YOUSSEF ** (Received at 12/6/1991)}
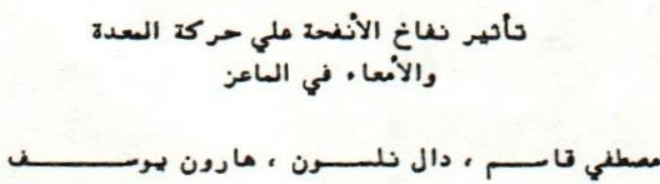

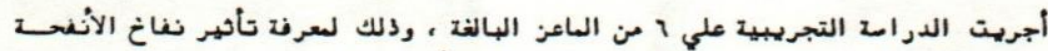

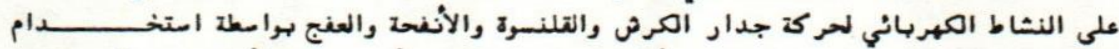

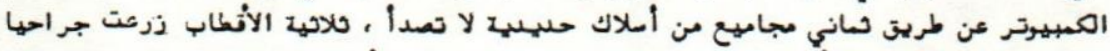

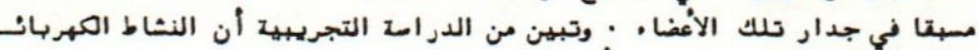

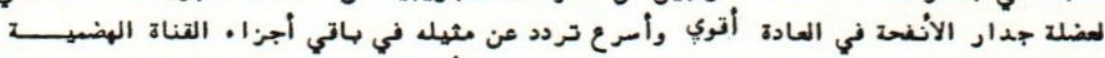

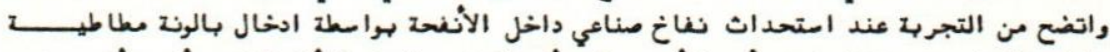

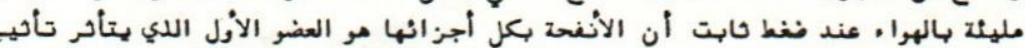

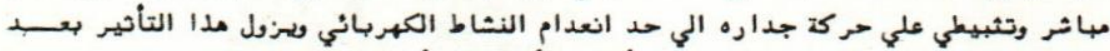

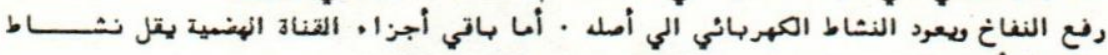

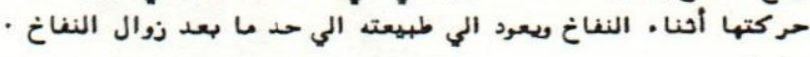

\section{SUMMARY}

In six adult goats, the motility pattern of the stomach and the proximal part of the duodenum was studied by means of electro-myography. Special attention was paid to the motility at the fundus and pyloric antrum of the abomasum.

Normally the myo-electrical contractions of the fundus and pyloric antrum are more stronger than that of the other gastric compartements. In this study, it was found that the amplitude and duration of the spiking activity at gastro-intestinal tract following inflation of a rubber balloon inside the abomasum varied from one organ to another. The motility was low and

* Dept. Vet. Clinical Med., College of Vet. Med. Univ. of Illinois, USA.

** Surgery Dept., Faculty Vet. Med., Assiut Univeristy. 


\section{MaM. KASSEM, et al.}

decreased in the frequency in all organs of the digestive tract, which were sêlected to study.

Fundus and pyloric antrum of the abomasum were greatly affected during abomasal distension. Migrating myo-electrical activity returned to the normal pattern, just after removal of the abomasal inflation strimulus.

\section{INTRODUCTION}

Impaction of th abomasum in goats occurs in animals confined to certain semi-desert glassland areas where the main grass grazed has tough awns such as Aristida (sp). Ingestion of large quantities of tough grass awns over a long time results in balls of the plant fiber in the abomasum. These balls may reach to $10 \mathrm{~cm}$ in diameter and be so many as to fill the abomasum. At this stage the cranial abdomen on the right shows distension. There is depressed appetite, loss of weight and increasing malaise. On palpation when the abdomen is relaxed particularly under the effect of tranquilizer. The distended abomasum can be felt with its somewhat resilient contents. The only treatment which offers hope of recovery is abomasotomy (OEHME' 1988).

Abomasal dilatation in sheep, is characterized by emaciation and ventral abdominal distension and somewhat bloat. Every affected animal had large palpable masses in right ventral portion of the abdomen. Rectal temperature ranged from 39.1 to $40.6^{\circ} \mathrm{C}$. All animals had tachycardia, Rumen motility decreased in most affected ewes (RUEGG, . GEORGE and EAST, 1988).

On the other hand, the clinical signs developed within 72 hours of pyloric obstruction in cattle. These cows failed to improve and remained inappetent and anorectic with decrease milk production. In each instance, the heart rate was increased and rumen motility was poor. Fecal output was decreased, with the feces being soft and dark (KELTON and FUBINI, 1989).

CATARSINI, et al. (1961) in an abattoir survey of the abomasum and forestomach of young sheep and goats reported that ulceration due to mechanical injury has a low incidence and little significance, and this observation propably. exends to housed animals in general.

Distension of the abomasum and i.itestine has powerful inhibitory influences on gastrointestinal motility and tone (JANSSON, 1969).

Other authors Concluded that inflation of the stomach caused two types of efferentdischarge patterns, eithet an increase in firing rate or decrease and in many instances, a complete suppression (SCRAKHERD and GRUNDY, 1982). 


\section{ABOMASAL DISTENSION}

It was found that in sheep the electrical events occuring in the smooth muscle of the abomasal wall could be observed simultaneously with abomasal emptying (BOLTON, MERRITT, CARLSON and DONAWICK, 1976).

The commonest of the contraction waves in the pylorus consisted of two or three successive contractions which occured immediately after the regular reticular contraction. In some cases the tonus in the pylorus suddenly increased and gradually returned to the initial level before the next reticular contraction. Upon this tonic wave usually three or five small contractions were superimposed. The incidence of this type of contraction was high during rumination. These were different, successive pressure changes which took place, regardless of the reticulo-ruminal contraction cycle. It may indicate the typical waves of peristalsis (OHGA, OTA and NAKAZATO, 1965).

Abomasal Fistulation did not significantly affect nutrient digestibility. It appears that digestive processes in fistulated steers closely approximate those in intact animals (HAYES, LITTLE and MITCHELT, 1964).

\section{MATERIAL and METHODS}

Six clinically healthy adult female goats weighing 80-135 lbs were conducted to the present experimental studies. Care was taken to select that remained placid in the experimental study. These animals were fed only on hay and water.

In each goat ten groups of electrodes were chronically implanted in the seromuscular layers of the forestomach wall (RUEKEBUSCH, 1970 and RUEKEBUSCH and BRADY, 1982) except omasal wall. Two group of electrodes were placed in diaphragmatic reticular wall, two groups in the ventral ruminal sac, two grous in the wall at fundic region and other, two groups in pyloric antrum of the abomasum and the last two groups were placed in the proximal part of the duodenum. Each two groups of the electrodes were implanted at 2 inches intervals.

Preoperative techniques were done in a routine manner, specially, fasting the selected goat overnight before surgery. Aseptic surgical procedures were always carried out under the effect of inhalation anaesthęsia (Halothane) with endotracheal intubation preceeded by intravenous injection of Surital ${ }^{2}$ in a dose of $6 \mathrm{mg} / \mathrm{lb}$ body weight.

The experimental goat was fixed on the dorsal recumbency. Laparotomy was done by longitudinal incision at the ventral midline, started from the umbilicus and extended cranially for about $6-8$ inches. The method used for implantation of the electrodes in

1 : Manufactured in USA byHolocarbon Laboratories, I.M

2 : Thiamylal sodium, Parke-Davis, Divot Warner Lambert Co., Morris Plain, N] 07950 USA.

Assiut Vet_Med.J., Vol. 26, No. 51, October 1991. 


\section{KASSEM, et alo}

the wall of gastro-intestinal tract, in the groups contain three electrodes, $2 \mathrm{~mm}$ apart was similar to that of RUCKEBUSEH and BUENO (1973).

Migrating myoelectrical contractions were recorded using three monopolar strainded stainless steel wire coated in tiflon (Biomed wire) ${ }^{3} 28$ gauge, $120 \mathrm{U}$ diameter and 25 inch in length. The free ends of electrodes were exteriorised through a stab wound in the left dorsal region of the flank just caudal to the last rib. The free ends of the electrodes were surrounded by adhesive, and fixed to the skin and also by string to a belt around the chest of the operated animal. From the belt, the electrodes were surrounded by adhesives and fixed to elastic wires which were directed to the electrical amplifier and IBM computer.

The abdominal wall was sutured by Dexon $2 / 0$ using simple continuous pattern. The skin wound was closed with simple interrupted sutures using Nylon or silk No. 0. Post-operative care was completed by injection of Phenylebutazone $(20 \%)$ as analgesic for each operated goat after surgery in a dose rate of $2 \mathrm{mq} / \mathrm{lb}$ body weight.

Recordings were not used until at least one week had been elapsed from the time of surgery. During the recordings continuous notes were done in order to facilitate the calculations afterwards. Myoelectrical activity was recorded by using eight channels chart recorded with universal amplifier.

\section{ABOMASAL CANNULATION}

For exteriorization the fundic part of the abomasum in goats, laparotomy was done at the ventrai midline cranial to the umbilicus for a distance about $20 \mathrm{~cm}$. A stab wound was performed at the ventral part of the fundus and plastic cannula was inserted in the wall of abomasum with its closed end, then inverted and burried by a further continuous suture.

The free end of the cannula was exteriorized through stab. wounds in the abdominal wall, on the left side of the laparotomy wound. The operation wound was closed by simple continuous suture using catgut. The skin wound was sutured by simple interrupted sutures using fine silk or Nylon.

\section{RESULTS}

To make clear the sequence of contraction ( $M M C$ ) of the rumen, reticulum, abomasum and duodenum a thin air balloon was placed in the fundic portion of the abomasum

3 : Cooner Wire Co., Chatsworth, CA, USA.

4 : Dist. by Burns Vet. Supply, Oakland, CA, 94621, USA.

Assiut Vet.Med.l, Vol. 26, Na. 51, October 1991. 


\section{ABOMASAL DISTENSION}

through artificial fislula in its wall. A constant pressure was mantained in all balloons of experimental goats.

Normally the myo-electrical contractions of the fundus and pyloric antrum of the abomasum are more stronger than that of the rumen and reticulum. The electromyographic records taken from the stomach and duodenum in goats, after abomasal distension show decrease in the motility of all gastric organs just after inflation of the balloon, Fig. 1.

The amplitude and duration of the spiking activity following abomasal distension with inflated rubber balloon vatied from one organ to another. The motility of the rumen, reticulum and duodenum was somewhat affected with abomasal disentension. Usually their motility was low and also decrease in the frequency and amplititude of migrating myoelectrical activity. Fundus and pyloric antrum were greatly affected with abomasal distension. The spikes of the motility was absent at the wall of th abomasum, during its distension, Fig. 1.

On removal of the abomasal inflation stimuluș, the spikes and migrating myo-electrical activity return somewhat to their normal pattern, usually just after deflation.

\section{DISCUSSION}

The clinical signs in this study, after abomasal distension were summerized as restlessness of the animal, colic, salivation, tachycardia and in some cases, the animal was relactant to recumbent position. These results are in agreement with that observed by RUEGG, et al. (1988) during abomasal dilatation in sheep. Contractions of the wall of rumen, reticulum and duodenum are somewhat affected with abomasal distension. This effect usually has supressed action on the motility of the fundus and pyloric antrum of the abomasum, or may lead to absence of abomasal contraction. These results coincide with that obtained by SCRATCHERD and GRUNDY (1982).

On the other hand after removal of the abomasal inflation stimulus, the spike activity and migrating myo-electrical contraction of the wall of gastric organs will return to their normal pattern, but with low amplitude. These results are similar to that discussed by SCRATCHERD and GRUNDY (1982).

In the same time GRUNDY and SCRATCHERD (1982) described that, the gastric motility and tone were markedly, reduced by distension of the duodenum and colon.

HAYES, LITTLE and MITCHELL (1964) discussed the influence of ruminal or abomasal fistulation on nutrient digestibility in beef steers. It has been assumed that the performance of fistulated ruminants is similar to that of intact animals.

Assiut Vet.Med.1, Vol. 26, Na. 51, October 1991. 


\section{KASSEM, et al.}

\section{REFERENCES}

Bolton, T.R.; Merritt, A.M.; Carlson, G.M. and Donawick, W.J. (1976): Normal abomasal electromyography and emptying in sheep and the effects of intrabomasal volatile fatty acid infusion. Am. J. Vet. Res., Vol. 37, No. 12: 1387-1392.

Catarsini, C.; Pantano, V. and De Franchesi, L. (1961): Cited by Angus, K.W. and Bunnatyne, C. (1970): Abomasal Ulceration in adult sheep: A report of two contrasting cases. Vet. Rec., Vol. 86, No. 18: 531-533.

Grundy, T. and Scratcherd, D. (1982): A splanchno- Vagal Component of the inhibition of gastric motility by disension of the intestines. Motility of the digestive Tract, 1st Ed. Raven press, New York, pp. 39-43.

Hayes, B.W.; Little, C.O. and Mitchell, G.E. (1964): Influence of Ruminal, Abomasal and Intestinal Fistulation on Digestion in steers. J. of Animal Science, 23: 764-766. Jansson, G. (1969): Acta Physiol. Scand., 75: 245-252.

Kelton, D.F. and Fubini, S.L. (1989): Pyloric obstruction after toggle-Pin Fixation of the left displaced abomasumin a cow. JAVMA, Vol. 194, No. 5: 677-678.

Oehme, F.W. (1988): Impaction of the abomasum in goats. Textbook of Large Animal surgery. 2nd Ed. Williams \& Wilkins Co., Baltimore USA, pp. 452-455.

Ohga, A.; Ota, Y. and Nakazato, Y. (1965): The movement of the stomach of sheep with special reference to the omasal movement. Jap. Vet. Sci., 27: 151-160.

Ruckebusch, Y. (1970): The electrical activity of the digestive tract of the sheep as an indication of the mechanical events in various regions. J. Physiol., 210: 857-882.

Ruckebusch, Y. and Brady, J.C. (1982): Recording and analysis of electrical activity of the gastro-intestinal tract. In techniques in digestive physiology. Elsevier Scientific publisher country clare Ireland.

Ruckebusch, Y. and Bueno, L. (1973): The effect of weaning on the motility of the small intestine in the calf. Br. J. Nutr., 30: 491-499.

Ruegg, P.L.; George, L.W. and East, N.E. (1988): Abomasal dilatation and emptying defect in a flock of suffolk ewes. JAVMA, Vol. 193, No. 12: 1534-1536.

Scratcherd, T. and Grundy, D. (1982): Nervous afferents from the upper gastro-intestinal tract which influence gastro-intestinal motility. Motility of the Digestive tract. Raven Press, New York, pp. 7-17.

Assiut Vet.Med.1, Vol. 26, No. 51, October 1991. 


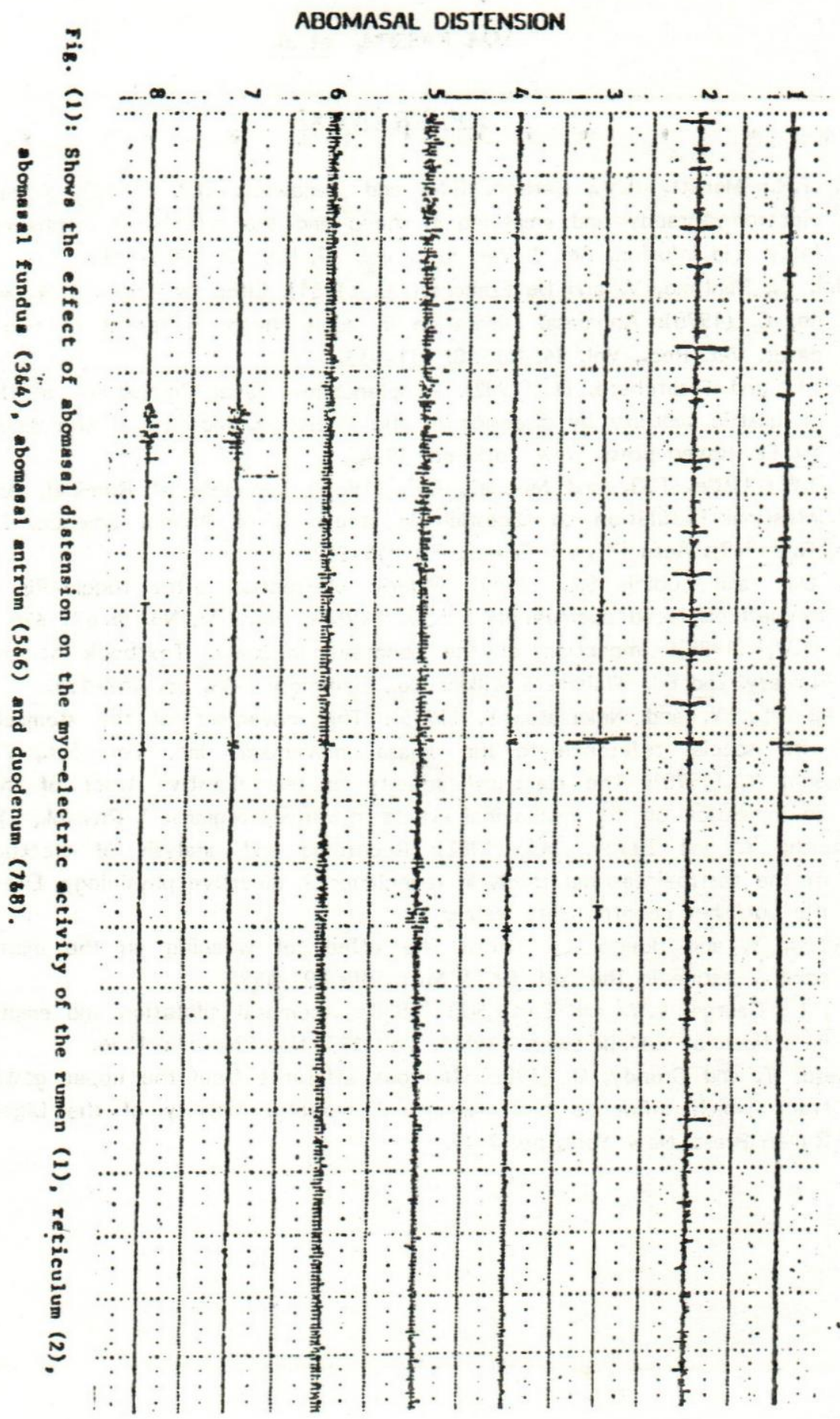

Assiut Vet.Med.J, Vol. 26, No. 51, October 1991. 